\title{
BORN TO BE BEAUTIFUL: \\ SEASON OF BIRTH INFLUENCES ADULT FEMALES' PHYSICAL ATTRACTIVENESS
}

\author{
Michą KanONOWicZ \\ michal.kanonowicz@gazeta.pl \\ University of Wrocław, Poland \\ PIOTR SOROKOWSKI \\ sorokowskipiotr@yahoo.co.uk \\ University of Wrocław, Poland \\ AgNIESZKA SOROKOWSKA \\ sorokowska@gmail.com \\ University of Wrocław, Poland
}

\begin{abstract}
Birth month in humans is associated with certain biological variables such as reproductive success, health and mortality rate. At the same time, physical attractiveness is regarded as one of the reliable markers of human health and genetic quality, which suggests that female attractiveness may vary according to their season of birth. To test this hypothesis, ratings of females' photographs from a popular Polish social networking website were analyzed. The sample included 5294 females aged 21-23 years. Results demonstrated that females born in spring (May) were rated as being significantly more attractive than those born in autumn (September and November).
\end{abstract}

Key words: season of birth, attractiveness, education, height

\section{INTRODUCTION}

All organisms respond to seasonal changes in the annual cycle - this fact is observed at all levels of species development (e.g. Brennen, 2001; Ewing, 2005; Hartig, Catalano \& Ong, 2007; Warren, 2003). What is more, it was shown that in many species the season of birth can be related with, for example, increased body size (Wilson, 1987, p. ?), birth sex ratio (Kent, 1992) or even social class (Smithers \& Cooper, 1984). In humans, a child's month of birth is also associated with its future life, involving such biological variables as weight, height (Weber et al., 1998), birthweight and reproductive success (Lummaa \& Tremblay, 2003). It might be also related to some psychological variables (or problems analyzed by psychologists) as, for example, educational achievements (Crosser, 1991; Plug, 2001; Russell \& Startup, 2001 ; Sharp, 1995), levels of physical activity and sports ability (Edgar \& O’Donoghue, 2005), occurrence of schizophrenia (review: Bradbury \& Miller, 1985), anorexia (Eagles, Andrew, Johnston, Easton \& Miller, 2001), autism (Stevens, Fein \& Waterhouse, 2001), alcoholism (Kunugi, Nanko, Watanabe, Skiba \& Kazamatsuri 1998), or sleep timing preferences (Natale, Adan \& Fabbri, 2009). 
One of the well documented effects is the relation of the season of birth and the health level of an individual (e.g. Moore, Cole, Poskitt, Sonko, Whitebread, McGregor \& Prentice, 1997). The explanation of this fact is not fully clear, although several hypotheses have been proposed. The most popular is that the observed differences are a consequence of prenatal exposure to such environmental factors as infections during the colder or rainy months (McGeehin \& Mirabelli, 2001; Moore et al., 1997). Simultaneously, results of various studies showed that human beauty can be considered an indicator of health. For example, unattractive waist-to-hip ratio might be associated with diabetes II, various cancers (breast, ovarian), cardiovascular diseases, etc. (review: Singh, 2002), whereas relatively longer legs can indicate smaller risk of major cardiovascular diseases and other health problems (review: Bogin \& Varela-Silva, 2010). What is more, short legs might be a result of adverse environmental conditions (diseases, nutritional deficiencies) in early childhood (review: Bogin \& Varela-Silva, 2010). Therefore, as certain aspects of health may be partly determined by the season of birth, and as human attractiveness might also be a health indicator, then the attractiveness might vary accordingly with the season of birth. In this study such hypothesis was tested with regard to female attractiveness.

\section{MATERIALS AND METHOD}

Females' personal advertisements from the www.fotka.pl website were analyzed. It is one of the largest social networking sites in Poland, where people add their profiles consisting of a description, some basic information about themselves and their pictures. An independent report (Megapanel PBI/Gemius, June 2008) estimated that this community has 2595251 independent users (the majority between 15 and 24 years of age). About $28 \%$ of all Polish girls between 15 and 24 years of age have their profiles on this website.

Everyone registered in that community can rate the physical attractiveness of other users from 1 to 11 . Despite very high average rates of photographs (in this study $M=10.18, S D=.35$, ranging between 7.21-11.0), differences between those ratings generally reflected real differences in attractiveness. They were highly correlated ( $r=.66, p<.0001$, statistics for 100 random profiles) with average ratings of 4 independent judges (psychology students).

Photographs on that website differ significantly in quality, angle, poses taken, outfit, composition, etc. Therefore, profiles with only one picture or pictures containing children, animals, couples, extensive nudity (e.g. girls in underwear only) were excluded from the study. The final sample included 5294 females aged 21-23 years. Height (data for $n=4999$ ) and education (data for $n=4652$ ) of subjects were controlled. The distribution of birth months of the subjects in the sample was as follows: January $(n=539)$, February $(n=510)$, March $(n=512)$, April $(n=431)$, May ( $\mathrm{n}=438)$, June $(n=436)$, July $(n=398)$, August $(n=342)$, September $(n=535)$, October $(n=430)$, November $(n=421)$ and December $(n=302)$. 


\section{RESULTS}

One way ANOVA $[F(11,5282)=2.4, p=.005]$ showed differences in the attractiveness of females born in various months (Fig. 1). Even when post hoc tests with Bonferroni corrections (computed because of large sample size) were used, females born in May $(10.22, \pm .017)$ were significantly more attractive than girls born in September $(10.15, \pm .015)$ and November $(10.14, \pm .017)$ (for May-September, $p=$ .049 ; for May-November, $p=.04$ ).

Significant differences were also found for height variation $[F(11,4987)=7.5$, $p<.0001)]$ but not for education level $[F(11,4640)=1.3, p=.22]$. Post hoc tests with Bonferroni corrections showed that females born in April (168.3 \pm .28$)$ and May (168.2 \pm .28$)$ were taller than females born in June (166.7 \pm .27$)$, July (166.5 $\pm .30)$, August (166.8 \pm .29$)$, September (166.9 \pm .25$)$ and October (165.9 \pm .28$)$ (all ps<.04).

To check if the statistical control of height may attenuate the effect of the month of birth on attractiveness, analysis of covariance (ANCOVA) was computed. The design of this study was 12 (month) x 4 (educational level - elementary, vocational, high school, university) with participants' height as covariate. In this analysis the main effect of months was still significant $[F(11,4476)=4.7, p<.001]$. Also,

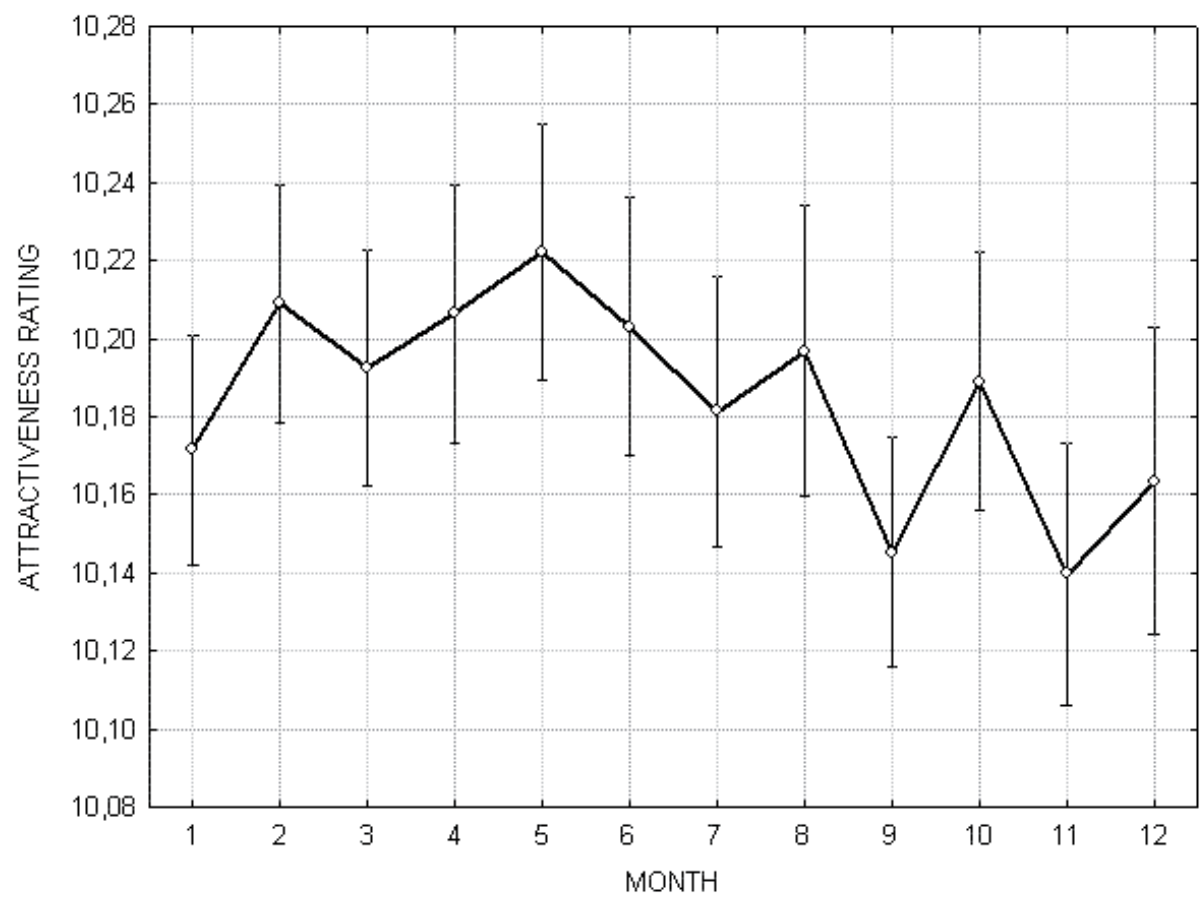

Figure 1. Effect of the month of birth on physical attractiveness.

Source: Authors. 
the simple effect was similar to the one in ANOVA analysis. Post hoc tests with Bonferroni corrections showed that females born in May (10.24) were significantly more attractive than girls born in September (10.15) and November (10.14) (for May-September, $p=.04$; for May-November, $p=.01$ ).

If we assume that the effect of the month of birth is underpinned by a natural, annually fluctuating factor, we should not only compare one month with another, but also one part of the year with another. Therefore, the abovementioned analyses were repeated for Polish seasons of the year (spring, summer, autumn, winter); $F(3,5003)=5.1760, p=.001$. Post hoc tests with Bonferroni corrections were used and females born in spring (10.21) or winter (10.2) were found to be significantly more attractive than girls born in summer $(10.17)$ or autumn $(10.16)$ (all ps <.04).

Correlations between height, education and attractiveness were also investigated. The only significant result was the correlation of height and education level $[r$ $=.07, p<.001$, for $n=4517]$.

\section{DISCUSSION}

The presented study demonstrated that Polish females born in winter and spring (especially in May) were rated as being significantly more attractive than those born in the summer and autumn months (particularly in September and November). The effect of season of birth on attractiveness might be associated with factors that fluctuate on the seasonal basis (e.g., nutrition, cold, heat, dehydration) and that may influence health status directly or indirectly (McGeehin \& Mirabelli, 2001).

One of the explanations of the obtained results might be the seasonal fluctuation of immunoglobulin levels (responsible for natural immunity) in newborns. In the Polish population immunoglobulin levels are the lowest between July and December and the highest between January and April. The difference for some markers (for example IgM) is very high - in autumn the level might be even 7 times lower than in spring - therefore, autumn is a period when many people fall ill and it is easy to be infected. At the same time, the newborns do not start to produce their own immunoglobulins on a larger scale until 2 months after birth (Ptak \& Ptak, 2000). They have some natural resistance received from the mother during pregnancy, but with time passing it decreases, and the newborn's protection is at its lowest about 3 months after birth. Therefore, the best (with regard to child's future health) period to give birth is between February and May, as the newborn has high natural immunity in the first months of its life and avoids the season when its vulnerability to diseases is the highest.

Another factor that might have influenced the results are the differences in diet in various seasons. In Poland, daily composition of diet varies seasonally, with more vegetables and fruits being available in summer and autumn. Therefore, at least in some part of the Polish population winter diet is low in important nutrients and vitamins. As maternal nutrition plays a critical role (particularly in the first few months) in fetal growth and development (e.g. Barker \& Clark, 1997) and person's future life (e.g. Kathleen Abu-Saad \& Fraser, 2010) deficiencies in winter diet should predominantly affect children born in autumn. In the case of the re- 
sults of the presented study it might explain the lower attractiveness of women born in September and November.

Other possible explanation of the influence of the season of birth on a person's attractiveness is that children born during spring are conceived in summer months, which in Poland is a holiday period (from around $20^{\text {th }}$ of June until the end of August - pupils, and until the end of September - students). As investigated, in Canada during holidays college students increase the frequency of both their sexual behavior and casual sexual encounters and in this time partners are chosen for short time relationships and only for sexual activity (Maticka-Tyndale, Herold \& Mewhinney 1998). It is possible that the main criterion used in selection of a partner for a short term relationships is physical attractiveness. Therefore, the result of such sexual encounters might be relatively high attractiveness of children born in spring.

Other results obtained in this study were rather incongruent with previous findings concerning the effect of birth season. Contrary to the general thesis that people born in autumn perform better academically no differences in education between people born in various months were found. However, some authors obtained such result as well (e.g. Wilson, 2000).

Another interesting result (not related to the hypothesis of the described study) was a correlation of height and education level. Such outcome is not surprising -psychological theories suggest that women prefer taller men because of the relationship between height and the perceived social status of a man (Barber, 1995; Jackson \& Ervin, 1992). The strong correlation between height and professional success was demonstrated in a number of studies (see: meta-analysis by Judge \& Cable, 2004). According to Frieze, Olson and Good (1990; see also: Egolf \& Corder, 1991; Hensley \& Cooper, 1987) only 3\% of 500 executives of the greatest American companies are shorter than $170 \mathrm{~cm}$, while over half of them measure more than $180 \mathrm{~cm}$ (the height of an average American is $175 \mathrm{~cm}$ ). Also American scientists are taller than average - examined professors were $5 \mathrm{~cm}$ taller than their peers (Hensley, 1993). In addition, taller people appear to earn more (Frieze et al., 1990; Persico, Postlewaite \& Silverman, 2004). In general, our study shows once again that height facilitates educational and social achievements.

The limitation of this study is that it was not a controlled experiment, but instead the faces from social networking site were used. A serious flaw of this kind of research might be the lack of control over variables that might have influenced the obtained results (but to overcome this problem, in this study, pictures containing children, animals, couples, extensive nudity were excluded). On the other hand, studies of this kind have higher ecological value. Their advantage is that the results are obtained in the 'real world', not the artificial, experimental conditions. Probably the participants expressed only the preferences that were real and important for them (see analyses of 'lonely hearts' columns by Koziel and Pawlowski (2003) or Lynn and Shurgot (1984)). In a relatively similar study, Lewis (2010) using photographs from Facebook (social networking site) showed that 'mixed-race' users were perceived as more attractive than 'one-race' users.

It is important to state that if the presented results are confirmed in further research, attractiveness should be included as a mediating variable in many studies 
regarding the season of birth. For example, it was demonstrated that there exists a relation between the season of birth and earnings (e.g. Buckles \& Hungerman, 2008; Plug, 2001). At the same time, French (2002) showed that physical attractiveness significantly correlated with earnings. Therefore, it is possible that different earnings of participants born in various seasons might be explained with their different physical attractiveness. Physical attractiveness has really high influence on how people are perceived (review: Etcoff, 1999). It is possible that many mechanisms might be explained in a similar way.

In conclusion, this study shows that attractiveness of females can be related to their season of birth - in Poland females born in spring and winter were found to be more attractive than females born in autumn and summer. Further experimental studies are necessary to confirm the obtained results. Research conducted among people living in harsh environmental conditions would also be interesting, because the results might show more significant variation.

\section{REFERENCES}

Abu-Saad, K., \& Fraser, D. (2010). Maternal nutrition and birth outcomes. Epidemiologic Reviews, 32, $5-25$.

Barber, N. (1995). The evolutionary psychology of physical attractiveness. Ethology and Sociobiology, $16,395-424$.

Barker, D.J.P., \& Clark, P.M. (1997). Fetal undernutrition and disease in later life. Reviews of Reproduction, 2, 105-112.

Bogin, B., \& Varela-Silva, M. I. (2010). Leg length, body proportion, and health: a review with a note on beauty. International Journal of Environmental Research and Public Heath, 7, 1047-1075.

Bradbury, T.N., \& Miller, G.A. (1985). Season of birth in schizophrenia: A review of evidence, methodology, and etiology. Psychological Bulletin, 98, 569-594.

Brennen, T. (2001). Seasonal cognitive rhythms within the Arctic. Circle: an individual differences approach. Journal of Environmental Psychology, 21, 191-199.

Buckles, K., \& Hungerman, D.M. (2008). Season of Birth and Later Outcomes: Old Questions, New Answers. NBER Working Paper No. w14573, 1-34.

Chichilenko, M.V., \& Barbarash, N.A. (2001). Effect of the season of birth on personality, health, and emotional stress in adolescents. Human Physiology, 27, 507-509.

Crosser, S.L. (1991). Summer birth date children: kindergarten entrance age and academic achievement. Journal of Educational Research, 84, 140-146.

Eagles, J.M., Andrew, J.E., Johnston, M.I., Easton, E.A., \& Miller, H.R. (2001). Season of birth in females with anorexia nervosa in Northeast Scotland. International Journal of Eating Disorders, 30, 167-175.

Edgar, S., \& O'Donoghue, P.G. (2005). Season of birth distribution of elite tennis players. Journal of Sport Sciences, 23, 1013-1020.

Egolf, D.B., \& Corder, L.E. (1991). Height differences of low and high job status, female and male corporate employees. Sex Roles, 24, 365-373.

Etcoff, N. (1999). Survival of the prettiest: The science of beauty. New York: Doubleday.

Ewing, L.L. (2005). Seasonal variation in Primate fertility with an emphasis on the male. American Journal of Primatology, 3, 145-160.

French, M.T. (2002). Physical appearance and earnings: Further evidence. Applied Economics, 34, 569-572.

Frieze, I.H., Olson, J.E., \& Good, D.C. (1990). Perceived and actual discrimination in the salaries of male and female managers. Journal of Applied Social Psychology, 20, 46-67.

Hartig, T., Catalano, R., \& Ong, M. (2007). Cold summer weather, constrained restoration, and the use of antidepressants in Sweden. Journal of Environmental Psychology, 27, 107-116.

Hensley, W.E. (1993). Height as a measure of success in academe. Journal of Human Behavior, 30, 40-46.

Hensley, W.E., \& Cooper, R. (1987). Height and occupational success: A review and critique. Psychological Reports, 60, 843-849. 
Judge, T.A., \& Cable, D.M. (2004). The effect of physical height on workplace success and income: Preliminary test of a theoretical model. Journal of Applied Psychology, 89, 428-441.

Kent, J.P. (1992). Birth sex ratios in sheep over six lambing seasons. Behavioral Ecology and Sociobiology, 30, 151-155.

Koziel, S., \& Pawlowski, B. (2003) Comparison between primary and secondary mate markets: an analysis of data from lonely hearts columns. Personality and Individual Differences, 35, 1849-1857.

Kunugi, H., Nanko, S., Watanabe, H., Skiba, K., \& Kazamatsuri, H. (1998). Season of birth of chronic alcoholics. Journal of Psychiatric Research, 32, 321-323.

Lewis, M.B. (2010). Why are mixed-race people perceived as more attractive? Perception, 39, 136-138.

Lummaa, V., \& Tremblay, M. (2003). Month of birth predicted reproductive success and fittness in pre-modern Canadian women. Proceedings of Royal Society B, 270, 2355-2361.

Lynn, M., \& Shurgot, B.A. (1984). Responses to Lonely Hearts Advertisements: Effect of reported physical attractiveness, physique and coloration. Personality and Social Psychology Bulletin, 10, 349-357.

Maticka-Tyndale, E., Herold, E.S., \& Mewhinney, D. (1998). Casual sex on spring break: Intentions and behaviors of Canadian students. Journal of Sex Research, 35, 254-264.

Megapanel PBI/Gemius, http://www.audience.gemius.pl/pages/display/witryny-uzytkownicy, retrieved: 30.06.2008.

McGeehin, M.A., \& Mirabelli, M. (2001). The potential impacts of climate variability and change on temperature-related morbidity and mortality in the United States. Environmental Health Perspective, 109, 185- 189.

Moore, S.E., Cole, T.J., Poskitt, E.M.E., Sonko, B.J., Whitebread, R.G., McGregor, I.A., \& Prentice, A. (1997). Season of birth predicts mortality in Rural Gambia. Nature, 388, 434.

Natale, V., Adan, A., \& Fabbri, M. (2009). Season of birth, gender, and social-cultural effects on sleep timing preferences in Human. Sleep, 32, 423-426.

Persico, N., Postlewaite A., \& Silverman, D. (2004). The effect of adolescent experience on labor market outcomes: The case of height. Journal of Political Economy, 112, 1019-1053.

Plug, E.J.S. (2001). Season of birth, schooling and earnings. Journal of Economic Psychology, 22, 641-660.

Ptak, W., \& Ptak, M. (2000). Podstawy immunologii. Kraków: Wydawnictwo Uniwersytetu Jagiellońskiego.

Russell, R.J.H., \& Startup, M.J. (1986). Month of birth and academic achievement. Personality and Individual Differences, 7, 839-846.

Sharp, C. (1995). A study of patterns of school entry and the impact of season of birth on school attainment. Education Research, 37, 251-265.

Singh, D. (2002). Female mate value at a glance: relationship of waist-to-hip ratio to health, fecundity and attractiveness. Neuroendocrinology Letters, 23, 81-91.

Smithers, A.G., \& Cooper, J. (1984). Social class and season of birth. The Journal of Social Psychology, 124, 79-84.

Stevens, M.C., Fein, D., \& Waterhouse, L.H (2000). Season of birth effects in autism. Journal of Clinical and Experimental Neuropsychology, 22, 399 - 407.

Warren, P.S. (2003). Winter dialects in the Bronzed Cowbird and their relationship to breeding-season dialects. Animal Behaviour, 65, 1169-1178.

Weber, G.W., Prossinger, H., \& Seidler, H. (1998). Height depends on month of birth. Nature, 391, 754-755.

Wilson, G. (2000). The effects of season of birth, sex and cognitive abilities on the assessment of special educational needs. Educational Psychology, 20, 153-66.

Wilson, R.T. (1987). Livestock production in central Mali: Factors influencing growth and live weight in agro-pastoral cattle. Tropical Animal Health and Production, 19, 103-114. 